OPEN ACCESS

Edited by:

Kenta Asahina,

Salk Institute for Biological Studies,

United States

Reviewed by:

Giorgio F. Gilestro,

Imperial College London,

United Kingdom

Amanda Jean Crocker,

Middlebury College, United States

*Correspondence: Jeffrey M. Donlea

jdonlea@ucla.edu

Specialty section:

This article was submitted to

Individual and Social Behaviors,

a section of the journal

Frontiers in Behavioral Neuroscience

Received: 15 September 2021 Accepted: 16 December 2021

Published: 20 January 2022

Citation:

Weiss JT and Donlea JM (2022) Roles for Sleep in Neural and Behavioral

Plasticity: Reviewing Variation in the

Consequences of Sleep Loss.

Front. Behav. Neurosci. 15:777799.

doi: 10.3389/fnbeh.2021.777799

\section{Roles for Sleep in Neural and Behavioral Plasticity: Reviewing Variation in the Consequences of Sleep Loss}

\author{
Jacqueline T. Weiss ${ }^{1,2}$ and Jeffrey M. Donlea ${ }^{1 *}$ \\ ${ }^{1}$ Department of Neurobiology, David Geffen School of Medicine at University of California, Los Angeles, Los Angeles, CA, \\ United States, ${ }^{2}$ Neuroscience Interdepartmental Program, University of California, Los Angeles, Los Angeles, CA, \\ United States
}

Sleep is a vital physiological state that has been broadly conserved across the evolution of animal species. While the precise functions of sleep remain poorly understood, a large body of research has examined the negative consequences of sleep loss on neural and behavioral plasticity. While sleep disruption generally results in degraded neural plasticity and cognitive function, the impact of sleep loss can vary widely with age, between individuals, and across physiological contexts. Additionally, several recent studies indicate that sleep loss differentially impacts distinct neuronal populations within memory-encoding circuitry. These findings indicate that the negative consequences of sleep loss are not universally shared, and that identifying conditions that influence the resilience of an organism (or neuron type) to sleep loss might open future opportunities to examine sleep's core functions in the brain. Here, we discuss the functional roles for sleep in adaptive plasticity and review factors that can contribute to individual variations in sleep behavior and responses to sleep loss.

Keywords: sleep, plasticity, review, memory, Drosophila

\section{INTRODUCTION}

Sleep is a physiological state that has been conserved across evolution, even noted in invertebrates lacking a centralized brain (Hendricks et al., 2000; Shaw et al., 2000; Zhdanova et al., 2001; Raizen et al., 2008; Singh et al., 2014; Nath et al., 2017). Although sleep's physiological functions remain poorly understood, sleep loss has been associated with deleterious effects on health and cognition (Rechtschaffen and Bergmann, 1995; Dinges et al., 1997; Durmer and Dinges, 2005; Spiegel et al., 2005; Banks and Dinges, 2007; Knutson et al., 2007; Grandner et al., 2010). Sleep varies based on previous waking experience (Ganguly-Fitzgerald et al., 2006; Huber et al., 2007; Hanlon et al., 2009; Keene et al., 2010; Beckwith et al., 2017; Kirszenblat et al., 2019; Milinski et al., 2021) throughout the lifespan (Roffwarg et al., 1966; Kales et al., 1967; Feinberg and Carlson, 1968; Cauter et al., 2000; Backhaus et al., 2007; Dijk et al., 2010; Feinberg and Campbell, 2010; Carrier et al., 2011; Vienne et al., 2016; Mander et al., 2017), and between species (Lyamin et al., 2008, 2017, 2018; Siegel, 2008; Lesku et al., 2012), suggesting that sleep has multiple functions. However, because sleep coincides with broad changes in neurophysiology and necessitates a loss of consciousness with reduced responsiveness to external threats, it is likely that sleep evolved, at least in part, to support brain function (Rasch and Born, 2013; Tononi and Cirelli, 2014). Notably, sleep is often 
elevated during periods of synaptic reorganization, including early development (Roffwarg et al., 1966; Shaw et al., 2000; Kayser et al., 2014), recovery from neural injury (Singh and Donlea, 2020; Stanhope et al., 2020), and memory consolidation (Walker et al., 2002; Ganguly-Fitzgerald et al., 2006). These findings each suggest that sleep supports plastic remodeling in the brain. Synaptic plasticity allows behavioral flexibility in response to external stimuli, and enables the processing and storage of information (Hughes, 1958; Zucker and Regehr, 2002; Cooke and Bliss, 2006). However, the underlying cellular and molecular mechanisms that support plasticity during sleep remain an area of intense investigation.

The impacts of sleep loss, interestingly, vary widely depending on age, environmental conditions, and genotype. While organisms typically recover from acute sleep disruptions relatively quickly, early-life sleep disruptions can prevent developmental plasticity during critical periods and result in long-lasting changes in circuit connectivity and behavior (Frank et al., 2001; Seugnet et al., 2011; Kayser et al., 2014). Conversely, some individuals withstand sleep loss with few consequences depending on the physiological conditions or genetic factors (Viola et al., 2007, 2012; Lyamin et al., 2008; Keene et al., 2010; Thimgan et al., 2010; Donlea et al., 2012; Lesku et al., 2012). In some cases, sleep disruption even provides an opportunity to weaken maladaptive memories (Poe, 2017). Examining the variables that can influence an individual's sensitivity to sleep loss could provide new insights into the core mechanisms of sleep-dependent plasticity. In this review, we will discuss roles for sleep in the maintenance of neural and behavioral plasticity during development, and learning/memory. Finally, we outline ethologically relevant conditions in which organisms can maintain neural and behavioral plasticity in the face of sleep loss.

\section{DEVELOPMENT}

Synaptic plasticity plays a crucial role in brain development, especially in the refining of neural connectivity through the process of pruning (Paolicelli et al., 2011). Defects in synaptic pruning during development are thought to contribute to atypical circuit function seen in neurodevelopmental disorders (Paolicelli et al., 2011; Konopaske et al., 2014; Tang et al., 2014; Cossío et al., 2017; Kim et al., 2017; Neniskyte and Gross, 2017). Daily sleep amounts peak in many species early in development, when the brain is undergoing significant plastic changes (Roffwarg et al., 1966; Jouvet-Mounier et al., 1970; Shaw et al., 2000; Kayser et al., 2014). Studies in humans have found that sleep disruption during development is associated with severe and lasting consequences for behavior and cognition (O'Brien et al., 2004; Halbower et al., 2006; Ednick et al., 2009). While these human studies provide a correlational link between impaired sleep and later cognition, several lines of animal studies described below indicate conserved roles for sleep in neurodevelopment of several species and begin to identify possible mechanisms by which sleep might influence brain development.
Rapid eye movement (REM) sleep is thought to play a particularly important role in development. Infants spend as much as $50 \%$ of their time asleep in REM, compared to $25 \%$ in adults (Roffwarg et al., 1966; Jouvet-Mounier et al., 1970). This period of increased REM sleep coincides with heightened formation and elimination of synapses in the developing mouse brain (Marks et al., 1995). Previous work found that REM deprivation, but not non-REM (NREM) deprivation, prevents the elimination of newly-formed dendritic spines in layer $\mathrm{V}$ pyramidal neurons in the developing mouse motor cortex ( $\mathrm{Li}$ et al., 2017). Further, elimination of recent spines during REM facilitates the development of new spines at nearby sites. While most newly formed spines are eliminated, persistent spines are strengthened by REM sleep. Notably, similar findings were observed in the adult mouse brain following motor learning ( $\mathrm{Li}$ et al., 2017).

A unique feature of REM sleep is the occurrence of myoclonic twitches, or spontaneous, discrete, spastic movements of the limbs (Tiriac et al., 2012; Blumberg et al., 2013; Sokoloff et al., 2020). These twitches occur throughout the mammalian lifespan, but are particularly abundant in infancy (Tiriac et al., 2012; Blumberg et al., 2013; Sokoloff et al., 2020, 2021). The development of myoclonic twitches depends on sensory feedback; the spatiotemporal organization of twitches is disrupted in newborn ErbB2 muscle-specific knockout mice which lack muscle spindles and exhibit impaired proprioception in adulthood (Blumberg et al., 2015). Muscle spindles are sensory receptors that relay changes in the length of muscles to the central nervous system and are necessary for intact proprioception (Kröger and Watkins, 2021). These findings suggest that twitches during sleep provide the developing brain with opportunities to refine immature sensorimotor maps and better coordinate limb movements. Twitching during early-life REM episodes, therefore, could facilitate the transformation of uncoordinated movements during infancy to the fine-tuned sensorimotor maps of an adult. Sensory feedback from twitching limbs are thought to contribute to motor learning and sensorimotor integration (Blumberg et al., 2013, 2020; Sokoloff et al., 2015; Rio-Bermudez and Blumberg, 2018; Glanz et al., 2021), as reafference from myoclonic twitches selectively activates brain regions such as the thalamus, cortex, hippocampus, and cerebellum in infant rats (Khazipov et al., 2004; Mohns and Blumberg, 2010; Tiriac et al., 2012; Sokoloff et al., 2015). Because reafference signals from self-movement are gated during waking, sleep disruptions that interfere with twitching, and their corresponding neuronal activity may disrupt sensorimotor maturation (Tiriac and Blumberg, 2016). While these studies provide an important and promising link between early-life sleep episodes and the development of mature sensorimotor representations, the underlying synaptic mechanisms and long-term consequences of myoclonic twitch disruptions remain to be characterized in detail.

A vital role for sleep in early life plasticity is shared across sensory circuits. The study of ocular dominance plasticity (ODP) induced by monocular deprivation (MD) in cats, for example, is a canonical model of critical period plasticity during development that is reliant upon sleep. During an early critical period for visual development, occluding one eye leads to enhanced visual 
cortex responses to inputs from the non-deprived eye (Hubel and Wiesel, 1970). Sleep enhances ODP; NREM sleep deprivation prevents enhancement of cortical plasticity, suggesting that sleep is vital for consolidating experience-dependent changes in ocular dominance following MD (Frank et al., 2001). More recent work has found that REM deprivation disrupts cortical plasticity after MD as well, perhaps by disrupting replay-like patterns of activity in the visual cortex (Bridi et al., 2015). Additionally, REM sleep following MD is sufficient to prevent reversal of ODP following subsequent manipulations such as further SD (Bridi et al., 2015), cortical inactivation (Jha et al., 2005), and inhibition of NMDA receptors (Aton et al., 2009). The dependence of ODP on REM sleep parallels studies of sensorimotor development described above, suggesting a vital role for REM sleep in permitting developmental refinement across sensory systems. The consolidation of ODP is also reminiscent of hippocampal memory consolidation during sleep (Diekelmann and Born, 2010; Rasch and Born, 2013). These studies suggest that sleep during development is necessary for the consolidation of plastic changes induced by waking experience, which likely guide appropriate behavioral adaptations to a changing environment. Since ODP (along with other forms of developmental plasticity) occurs during a tightly restricted critical period of development, sleep disruptions early in life could have long-lasting effects on neurophysiology and behavior.

Ontogenetic changes in sleep are conserved; sleep amount and intensity are increased early in life for invertebrates, such as the fruit fly, just as they are in mammals (JouvetMounier et al., 1970; Shaw et al., 2000). In Drosophila, $24 \mathrm{~h}$ of sleep deprivation following eclosion leads to longterm learning deficits, whereas adults recover from the same duration of sleep loss after one night of recovery sleep (Seugnet et al., 2011). These chronic learning impairments are likely connected with altered dopamine signaling, and can be dampened either by blocking D1 receptor activity during early life sleep loss or by elevating dopamine signaling during the days after developmental sleep deprivation (Seugnet et al., 2011). Additionally, young sleep-deprived male flies, but not mature flies, show deficits in courtship behavior as adults (Seugnet et al., 2011; Kayser et al., 2014). These courtship deficits are accompanied by decreased size of an olfactory glomerulus associated with perception of social pheromones, caused by impaired developmental growth (Kayser et al., 2014). Similarly, 1 week of early life sleep disruption impairs later social bonding in adult prairie voles (Jones et al., 2019). In this study, sleep disruption occurred during the third and fourth weeks of life, which likely falls during a critical period for maturation of GABAergic circuits that contribute to sensory integration (Gogolla et al., 2014). Notably, early life sleep deprivation in prairie voles leads to an increase in parvalbumin immunoreactivity in the primary sensory cortex, a brain region relevant to social bonding (Jones et al., 2019). Chronic changes in parvalbumin signaling could disrupt sensory processing and social behavior by altering excitatory/inhibitory balance (Yizhar et al., 2011). Together, these studies demonstrate that early life sleep is vital for developmental growth of rapidly growing brain regions across many species, and that disrupted sleep during development can result in lasting effects on adult circuitry and behavior.

While human studies have not yet revealed a mechanistic understanding of how sleep promotes neural and cognitive development, animal models indicate that sleep's role in neurodevelopment is evolutionarily ancient. Model system studies, such as those in flies and mice discussed above, have begun to examine how sleep modulates synaptic connectivity in a variety of developing sensory circuits. Further studies in these systems may reveal interventions that facilitate healthy development during insufficient sleep (Seugnet et al., 2011; Kayser et al., 2014; Jones et al., 2019).

\section{LEARNING AND MEMORY}

In a variety of species, sleep is required for several stages of memory formation and processing (Walker et al., 2002; Graves et al., 2003; McDermott et al., 2003; Ganguly-Fitzgerald et al., 2006; Seugnet et al., 2008; Krishnan et al., 2016). Indeed, sleep deprivation leads to impaired encoding (Walker et al., 2002; Yoo et al., 2007; Seugnet et al., 2008), consolidation (Graves et al., 2003; Diekelmann and Born, 2010), and retrieval (Gais et al., 2007; Lo et al., 2016; Montes-Rodríguez et al., 2019; Heckman et al., 2020) of recent associations. While even a brief nap restores memory in some assays (Seugnet et al., 2008; Ong et al., 2020), other learning and memory impairments persist after days of recovery sleep (Havekes et al., 2016; Yamazaki et al., 2020; Wu et al., 2021). While it is not clear why recovery from sleep loss varies between these conditions, studies have detected several types of longer-lasting cellular and molecular changes that persist after recovery sleep, including altered gene expression (Gaine et al., 2021), protein synthesis (Tudor et al., 2016; Lamon et al., 2021), and circuit connectivity (Weiss and Donlea, 2021). Interestingly, some types of memories seem to be more vulnerable to sleep loss than others. For example, procedural memories and memories acquired with a conscious motivation or reward benefit from sleep more than declarative or unmotivated memories (Stickgold and Walker, 2007; Diekelmann and Born, 2010). In Drosophila, sleep deprivation disrupts consolidation of appetitive sugar reward memories in fed flies, but in not starved flies (Chouhan et al., 2021). Together, these studies indicate that sleep deprivation likely does not have a universal effect on learning and memory, but varies based on physiological, environmental, and behavioral factors.

While the negative impacts of sleep loss on memory formation are typically detrimental, it is possible that targeted sleep disruption could be used to prevent the consolidation of maladaptive memories. Some studies, for instance, suggest that sleep deprivation could be used following trauma to degrade fear memories in patients with post-traumatic stress disorder (PTSD). Studies by Vanderheyden et al. (2015) compared sleep patterns of rats that were susceptible to developing PTSDlike symptoms after trauma to those that were resilient. While susceptible rats exhibited an increase in REM sleep in the hours following the traumatic event, resilient rats slept little during this period (Vanderheyden et al., 2015). Heightened 
REM sleep following trauma could lead to consolidation and reactivation of the trauma memory, preventing fear extinction, and resulting in generalization of the fear memory (Poe, 2017). Traumatic events drive activation of the mammalian locus coeruleus (LC) (Passerin et al., 2000; Naegeli et al., 2018), a collection of noradrenergic cells that promote long-term potentiation (LTP) (Izumi et al., 1992; Thomas et al., 1996; Izumi and Zorumski, 1999) and are generally quiescent during REM sleep (Foote et al., 1980). Elevated LC activity during REM sleep following a traumatic event can contribute to enhancement of recently formed emotional memories as seen in PTSD (Wassing et al., 2019). Therefore, behavioral sleep deprivation or pharmacological REM suppression following a traumatic event could lead to interventions to prevent the development of PTSD (Vanderheyden et al., 2014, 2015; Poe, 2017). Conversely, given the importance of sleep in memory consolidation (Rasch and Born, 2013) and emotional processing (Palmer and Alfano, 2017; Tempesta et al., 2018), sleep loss following a traumatic event could prevent consolidation of fear extinction memory in other conditions (Pace-Schott et al., 2015). Recent human studies have produced mixed results (Porcheret et al., 2015; Kleim et al., 2016; Cohen et al., 2017), indicating that the role for sleep in consolidating and/or maintaining traumatic memories varies with context or time elapsed since trauma. Further studies will be required to examine the therapeutic potential of sleep manipulations more clearly.

\section{Synaptic Plasticity and Homeostasis}

Although the primary function or functions of sleep are not understood, evidence suggests a strong relationship between sleep and plasticity (Frank et al., 2001; Tononi and Cirelli, 2014). Sleep loss leads to impairments in the plastic processes of learning and memory (Diekelmann and Born, 2010; Rasch and Born, 2013). One prominent hypothesis posits that sleep's function is the renormalization of synaptic strength via downscaling of synapses that are potentiated during wake, thereby constraining excitability and restoring signal-to-noise ratios for neuronal firing (Tononi and Cirelli, 2014). Learning about the environment during waking experience requires strengthening of synapses (Clem and Barth, 2006; Gruart et al., 2006; Tye et al., 2008). According to this synaptic homeostasis hypothesis, sleep deprivation leads to cognitive deficits due to saturation of synaptic connections (Tononi and Cirelli, 2014). Evidence supporting the role of synaptic downscaling during sleep exists in a variety of species (Gilestro et al., 2009; Vyazovskiy et al., 2009; Bushey et al., 2011). At the molecular level, synaptoneurosomes from the cortex and hippocampus of adult rats display increased protein levels of GluA1-containing AMPA receptors after spontaneous and forced wake than after sleep (Vyazovskiy et al., 2008). Sleep has been found to promote synaptic downscaling in the mouse forebrain by internalizing AMPA receptors via the immediate early gene Homer1 (Diering et al., 2017). In addition, the size of the axon-spine-interface, an ultrastructural measure of synaptic strength, increases after several hours of wake compared to sleep in several mouse brain regions (Vivo et al., 2017, 2019; Spano et al., 2019). At the electrophysiological level, amplitude and/or frequency of miniature excitatory postsynaptic currents in several regions of the rodent brain increase during wake and after sleep loss, and decline following spontaneous sleep and recovery sleep (Liu et al., 2010; Bjorness et al., 2020; Khlghatyan et al., 2020). Additionally, firing rates of hippocampal and cortical neurons have been shown to increase with wake and decrease with sleep (Lubenov and Siapas, 2008; Vyazovskiy et al., 2008, 2009; Huber et al., 2013; Norimoto et al., 2018). Studies in Drosophila have also found increases in abundance of presynaptic and postsynaptic markers following sleep loss, consistent with the hypothesis of net potentiation during wake (Gilestro et al., 2009; Bushey et al., 2011; Huang et al., 2020; Weiss and Donlea, 2021). Additional work in the fruit fly has found that acute sleep induction is sufficient to reduce abundance of transcripts (Dissel et al., 2015) or protein (Weiss and Donlea, 2021) of synaptic components.

While evidence clearly suggests a role for sleep in synaptic downscaling in some circumstances, other studies have reported synaptic potentiation during sleep (Frank et al., 2001; Aton et al., 2013 , 2014). Short periods of sleep loss decrease the number of dendritic spines in the CA1 region of the hippocampus due to increased activity of the actin-binding protein cofilin (Havekes et al., 2016). Suppressing cofilin activity in hippocampal neurons prevents spine loss and cognitive deficits following sleep deprivation, suggesting that disruption of synaptic potentiation during sleep deprivation can lead to defects in memory consolidation (Havekes et al., 2016). Similarly, sleep deprivation leads to decreased spine density in the dentate gyrus (Raven et al., 2019), and disrupts the formation of new spines following learning (Yang et al., 2014). These data indicate that, although evidence supports a general trend for synaptic downscaling during sleep, it is likely that different classes of synapses undergo different forms of plasticity during sleep or that sleep alters synaptic organization differently depending on the organism's developmental state and recent experience.

Several recent studies have sought to understand whether sleep loss differentially affects distinct classes of neurons within a single circuit or brain region. The Drosophila mushroom body (MB), which encodes olfactory associative memories, provides an ideal opportunity to examine the local effects of sleep loss on synapse organization. Heroic efforts have untangled the organization of the fly $\mathrm{MB}$ with the development of genetic drivers to label each cell type, often with single-cell resolution (Aso et al., 2014a,b) and serial reconstruction of electron micrographs have led to a detailed connectome of the $\mathrm{MB}$ circuitry (Li et al., 2020; Scheffer et al., 2020). These studies show that the Drosophila MB is an associative learning center that is divided into 15 zones defined by non-overlapping arborization of several cell types, including cholinergic Kenyon Cells (KCs), reinforcing dopaminergic neurons (DANs), and mushroom body output neurons (MBONs) which mediate behavioral valence output (Aso et al., 2014a). Associative engrams can be localized to individual zones of the $\mathrm{MB}$ lobes, where plasticity in the connections between odor-encoding $\mathrm{KCs}$ and valence-driving MBONs determines the fly's behavioral response to odorant stimuli (Aso et al., 2014b; Hige et al., 2015; Owald et al., 2015). Since sleep loss prior to training can impair acquisition/shortterm memory and disrupting sleep after training prevents 

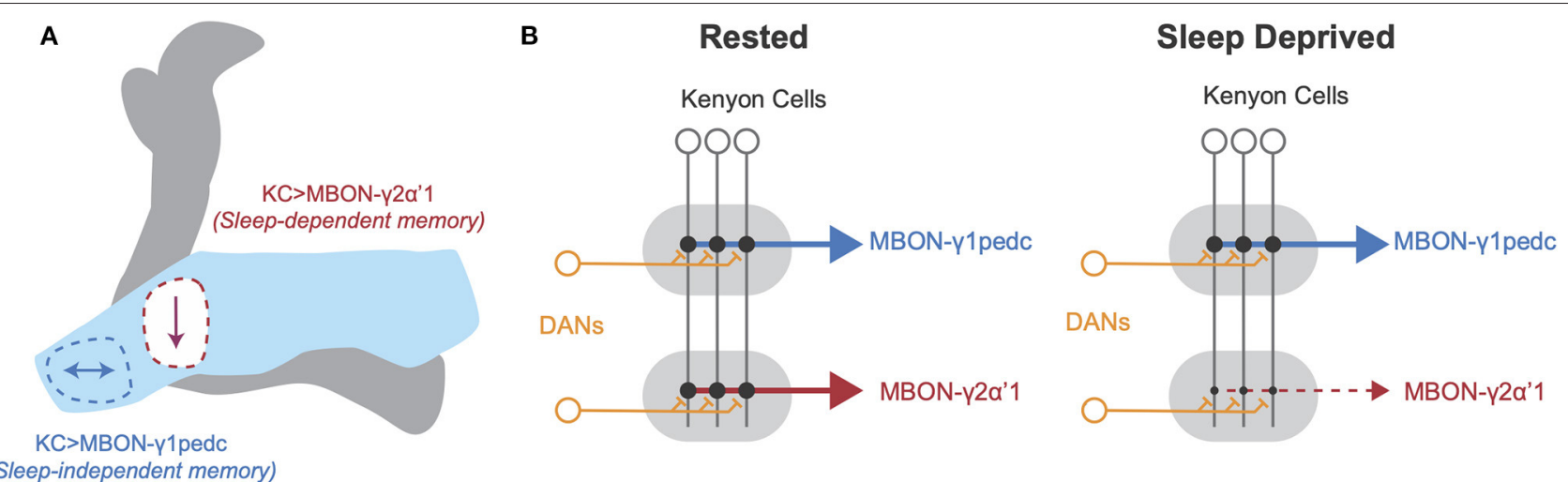

(Sleep-independent memory)

FIGURE 1 | Schematic of local plasticity in Drosophila mushroom body after sleep loss. (A) Schematic illustration of Drosophila mushroom body. The $\gamma$ lobe (light blue) contains the $\gamma 1$ compartment, outlined in blue, and the $\gamma 2$ compartment, outlined in red. Arrows represent changes in connectivity from Kenyon cells to MBON- $\gamma 1$ pedc (left, blue) and MBON- $\gamma 2 \alpha^{\prime} 1$ (right, red). Appetitive memory encoded at KC $>$ MBON- $\gamma 1$ pedc synapses is resilient to sleep loss, but appetitive memory encoded at $\mathrm{KC}>\mathrm{MBON}-\gamma 2 \alpha^{\prime} 1$ synapses is impaired by sleep loss. (B) Schematic of connectivity between neuronal cell types in MB in rested (left) and sleep deprived brains (right). $\mathrm{KC}$ axons innervate tiled zones that each receive input from distinct DANs and provide input to unique MBONs. After $\mathrm{SD}$, KC>MBON- $\gamma 1$ pedc connectivity is unchanged, but KC>MBON- $\gamma 2 \alpha$ '1 connectivity decreases. Based on findings from Weiss and Donlea (2021) and Chouhan et al. (2021).

memory consolidation (Ganguly-Fitzgerald et al., 2006; Seugnet et al., 2008), it is likely that sleep deprivation alters either synaptic connectivity or plasticity in MB circuits. Overnight sleep deprivation selectively upscales synapses of cholinergic memoryencoding KCs, but not other cell types in the MB, including DANs or large, inhibitory interneurons (Weiss and Donlea, 2021). Further, not all types of KC output synapses are equally impacted by sleep loss; output connections from KCs to different classes of post-synaptic target neurons show wide variations in abundance following sleep loss.

Interestingly, studies by Chouhan et al. (2021), found that flies housed without food did not require sleep after appetitive conditioning to form new memories, unlike fed flies. While appetitive memory is encoded in the $\mathrm{KC}>\mathrm{MBON}-\gamma 2 \alpha$ ' 1 circuit in fed flies and is sensitive to sleep loss, appetitive memory is encoded in $\mathrm{KC}>\mathrm{MBON}-\gamma$ lpedc circuitry in starved flies, and remains intact with sleep loss (Chouhan et al., 2021). Additionally, Weiss and Donlea (2021) found that sleep loss led to decreased connectivity between KCs and MBON$\gamma 2 \alpha$ ' , necessary for sleep-dependent memory consolidation, while $\mathrm{KC}>\mathrm{MBON}-\gamma$ lpedc connections, dispensable for sleepdependent memory consolidation, were unaffected. Sleep loss could therefore disrupt consolidation of recent appetitive memories in fed flies by reducing overall connectivity between KCs and MBON- $\gamma 2 \alpha$ '1 (see Figure 1). Because plasticity rules can differ widely between MB sub-circuits (Hige et al., 2015), environmental conditions during learning likely influence the strength, retention, and/or decay time of a particular association. These results suggest that different zones of the MB exhibit distinct plasticity rules during sleep, likely based on learning paradigm, internal state, and other previous experience.

Supporting the idea of region and circuit specific changes in plasticity with SD, Puentes-Mestril et al. (2021) examined the effects of sleep loss on ribosome-bound transcripts for activity-dependent regulators of plasticity in excitatory pyramidal neurons and inhibitory parvalbumin-expressing interneurons. While both classes of neurons show increases in plasticitymediating transcripts in the cortex following sleep loss, SD has little effect on abundance of these transcripts in both cell types in the hippocampus (Puentes-Mestril et al., 2021). Additional work suggests that certain cell types in the mouse hippocampus likely have privileged roles in memory consolidation during sleep (Delorme et al., 2021). Sleep deprivation leads to activation of inhibitory somatostatin-expressing (Sst+) interneurons in the hippocampus, likely due to inputs from increasingly active cholinergic neurons (Delorme et al., 2021). Both pharmacological activation of cholinergic neurons and chemogenetic activation of Sst+ cells in the dorsal hippocampus in the absence of SD leads to deficits in sleep-dependent memory consolidation (Delorme et al., 2021). Notably, both Delorme et al. (2021) and Weiss and Donlea (2021) found that sleep deprivation enhances cholinergic signaling onto GABAergic interneurons in learning/memory-related circuits, which likely increases inhibition onto memory-encoding neurons (see Figure 2). Enhanced hippocampal inhibition due to increased Sst+ activity during SD correlates with impairment of memory consolidation by disrupting LTP (Vecsey et al., 2009; Havekes et al., 2016), the reactivation of memory-encoding cells (Stefanelli et al., 2016; Clawson et al., 2021), or hippocampal oscillations (PuentesMestril et al., 2019). Similarly, while some inhibition from the Drosophila APL interneurons onto KCs is necessary to maintain spatial and temporal sparseness of odor encoding (Lei et al., 2013; Lin et al., 2014), excess inhibition would likely prevent encoding of new odor associations and reactivation of existing memory traces. Interestingly, GABAergic signaling from dorsal paired medial (DPM) and anterior paired lateral (APL) promotes sleep at night, suggesting that these interneurons may be recruited by increased $\mathrm{KC}$ activity during $\mathrm{SD}$ to promote sleep and sparsen KC representations (Haynes et al., 2015). These studies in both mice and Drosophila suggest that increased 


\section{A Fruit Fly Mushroom Body}
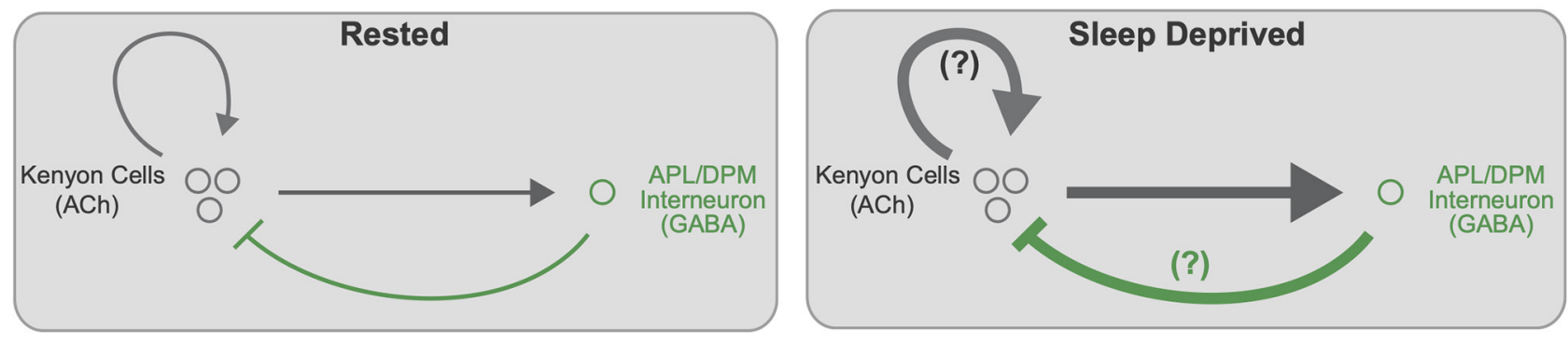

B

Mouse Hippocampus
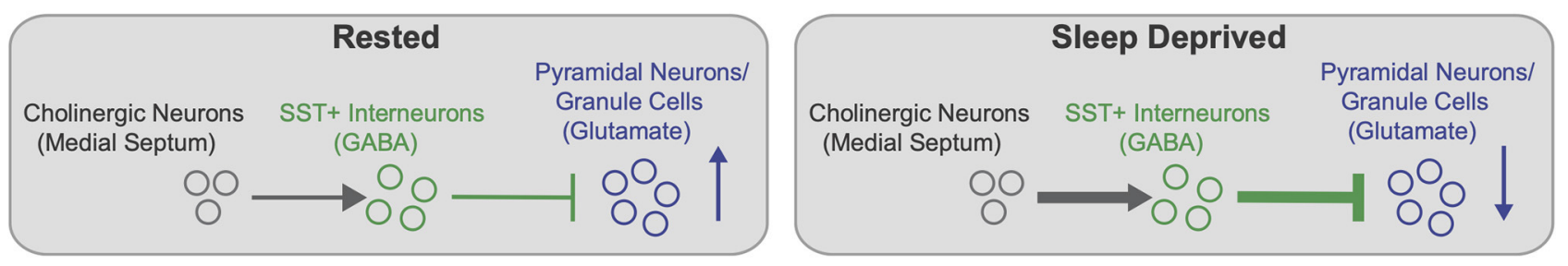

FIGURE 2 | Cell type specific effects of sleep loss on memory-encoding circuits. (A) Schematic of connectivity between memory-encoding KCs and APL/DPM interneurons in the Drosophila MB in rested (left) and sleep deprived (right) flies. Cholinergic KCs activate GABAergic interneurons, which provide feedback inhibition onto KCs. KCs also synapse back onto other KCs. After SD (right), KC>APL connectivity strengthens, presumably increasing inhibition back onto KCs. KC>KC synapses may also strengthen, further contributing to increased KC>APL connectivity. Increased inhibition from APL/DPM after SD could dampen KC>KC excitation and promote recovery sleep. Based on findings from Weiss and Donlea (2021). (B) Schematic of hippocampal circuitry including cholinergic neurons in the medial septum to the mouse hippocampus in rested (left) and sleep deprived (right) mice. Cholinergic neurons activate GABAergic SST+ interneurons in the hippocampus, which inhibit memory-encoding pyramidal neurons/granule cells (principal neurons). After SD (right), enhanced cholinergic signaling increasingly activates SST+ interneurons, thereby heightening inhibition and reducing activity of hippocampal pyramidal neurons and granule cells. Based on findings from Delorme et al. (2021).

cholinergic signaling disrupts learning and memory after sleep deprivation, and that inhibitory drive onto memory-encoding neurons could be recruited to compensate. While these studies find complementary effects of sleep loss in the fly and mouse, these results use different approaches; Weiss and Donlea (2021) measure synaptic active zone reporters in the fly MB while Delorme et al. (2021) and Puentes-Mestril et al. (2021) quantify hippocampal transcript levels of activity-dependent immediate early genes. Additional studies will be required to directly test the relationship between connectivity changes and cell-type specific changes in activity. Ultimately, characterizing the subsets of synapses, cell types, and circuits that are most sensitive to sleep loss will help elucidate the mechanisms by which SD impairs behaviors such as learning and memory.

Sleep not only balances synaptic connectivity, but also influences neuronal firing patterns. In the rodent frontal cortex, fast spiking pyramidal cells show decreased activity during NREM sleep, while slow firing neurons increase their firing rate (Watson et al., 2016). Similar findings were observed in the mouse primary visual cortex, and these changes in firing rates were disrupted by a period of brief sleep deprivation (Clawson et al., 2018). Pyramidal neurons that are active during sleep spindles, oscillatory activity that promotes plasticity underlying memory formation (Schabus et al., 2006; Rasch and Born, 2013; Cairney et al., 2018), are increasingly active over the course of slow-wave sleep (SWS), whereas spindleinactive pyramidal neurons show decreased activity during
SWS (Niethard et al., 2021). These results indicate that sleep can increase the signal-to-noise ratio of neuronal responses by increasing the activity of sparsely firing neurons with the highest selectivity while reducing noise by decreasing activity of faster spiking, less selective neurons (Clawson et al., 2018). Interestingly, sleep during early-life ODP in mice is vital for firing rate homeostasis, indicating a potential life-long role for sleep in normalizing neuronal activity (Hengen et al., 2016; Pacheco et al., 2021).

\section{RESILIENCE TO SLEEP LOSS \\ Ethological Context}

While sleep contributes to many forms of experience-dependent plasticity as described above, individuals can show a wide variation in their responses to sleep loss. Sleep is homeostatically regulated across many species, but both extrinsic and intrinsic factors can influence the responses of an organism to specific sleep challenges. Food-deprived Drosophila, for instance, typically reduce their sleep, presumably to maximize foraging opportunities (Keene et al., 2010; Thimgan et al., 2010; Yurgel et al., 2019). While acute sleep-deprivation is typically accompanied by impaired memory and a homeostatic increase in sleep, flies that lose sleep overnight during food deprivation can retain intact memory formation and show little, if any, sleep rebound (Thimgan et al., 2010). Similarly, socially naïve male flies will also forego sleep when paired overnight with a female 
TABLE 1 | Summary of experimental or ethologically-relevant conditions that reduce sleep in several species.

\begin{tabular}{|c|c|c|c|c|}
\hline Species & Manipulation & Sleep response & Behavioral response & References \\
\hline \multirow[t]{4}{*}{ Drosophila melanogaster } & Sleep deprivation & Decreased sleep, homeostatic rebound & $\begin{array}{l}\text { Impaired learning, } \\
\text { STM and LTM }\end{array}$ & $\begin{array}{l}\text { Ganguly-Fitzgerald } \\
\text { et al., 2006; Seugnet } \\
\text { et al., 2008; Li et al., } \\
2009\end{array}$ \\
\hline & Starvation & Decreased sleep, no rebound & Intact memory & $\begin{array}{l}\text { Keene et al., 2010; } \\
\text { Thimgan et al., 2010; } \\
\text { Yurgel et al., } 2019\end{array}$ \\
\hline & Stimulants & Decreased sleep & Not measured & $\begin{array}{l}\text { Hendricks et al., 2000; } \\
\text { Shaw et al., 2000; } \\
\text { Andretic et al., 2005 }\end{array}$ \\
\hline & Courtship & Decreased sleep, no rebound & Not measured & $\begin{array}{l}\text { Beckwith et al., 2017; } \\
\text { Machado et al., } 2017\end{array}$ \\
\hline Frigatebirds & Migration & Decreased sleep in flight, rebound on land & Not measured & Rattenborg et al., 2016 \\
\hline Sandpipers & Mating season & Decreased sleep & $\begin{array}{l}\text { Mating success } \\
\text { positively correlated } \\
\text { with amount of sleep } \\
\text { loss }\end{array}$ & Lesku et al., 2012 \\
\hline Cetaceans & Postpartum & Little to no sleep & Not measured & $\begin{array}{l}\text { Lyamin et al., 2005, } \\
2007\end{array}$ \\
\hline Fur seals & In seawater & Greatly reduced REM, no REM rebound & Not measured & Lyamin et al., 2018 \\
\hline
\end{tabular}

fly (Beckwith et al., 2017; Machado et al., 2017). This effect can be replicated by activating pheromone sensing neurons or courtship control circuits and, like starvation-induced arousal, is not followed by a sleep rebound. Similarly, the ability to temporarily offset the need for sleep has also been found in vertebrate species. Fur seals suppress REM sleep for days or weeks when foraging in seawater, accompanied by little to no REM rebound (Lyamin et al., 2018). Migratory frigate birds can reduce the time that they spend asleep by over $90 \%$ for $\sim 10$ days while continuously in flight over the Pacific Ocean compared to their sleeping patterns on land (Rattenborg et al., 2016). Similarly, Arctic male sandpipers suppress sleep for a roughly 3 week period annually while they compete for mating partners (Lesku et al., 2012). During mating season, the sun never sets in the high Arctic, allowing males to engage in unlimited visual courtship displays. Because mating success is correlated with the amount of time that male sandpipers spend awake, there is likely selective pressure for genetic factors that can allow male sandpipers to withstand prolonged sleep loss without accruing cognitive deficits or sleep drive. Constant sunlight during this period likely interacts with social and reproductive cues, enabling males to forego sleep for an extended period. Social behaviors can also drive contexts in which mammals can delay the need for sleep. Whales and dolphins, for example, can nearly fully suppress sleep for up to a month after giving birth with no recorded physiological consequences (Lyamin et al., 2005). Importantly, vertebrate sleep stages are characterized by electrophysiological signatures measured with electroencephalography (EEG) (two process model), whereas Drosophila sleep is defined by behavioral criteria such as quiescence and increased arousal threshold (Hendricks et al., 2000; Shaw et al., 2000). Recent work has begun to investigate whether sleep in Drosophila is composed of distinct stages (Yap et al., 2017; Raccuglia et al., 2019; Tainton-Heap et al., 2021), which may account for variations in plasticity and responses to sleep loss discussed above. While mechanistic studies are not feasible in many of the species mentioned here, the range of contexts in which sleep need can be temporarily offset provides exciting opportunities to understand when sleep is required for plasticity (see Table $\mathbf{1}$ ).

\section{Intrinsic Factors}

Resilience to sleep loss can also be influenced by intrinsic factors that vary between individuals. Human subjects exhibit reliable, stable responses to repeated episodes of sleep loss, suggesting that sensitivity to sleep loss can be a durable trait over time (Dennis et al., 2017; Yamazaki and Goel, 2019). Naturally occurring genetic polymorphisms coincide with an individual's response to sleep loss in flies and humans (Viola et al., 2007, 2012; Donlea et al., 2012; Satterfield et al., 2015). In two of these studies, the same genetic alleles correlated with reduced cognitive impairments and dampened homeostatic sleep pressure after prolonged waking, indicating that the identified loci could contribute to protecting neural functions during sleep loss (Viola et al., 2007; Donlea et al., 2012). Interestingly, the identified human alleles in per3 and $t n f \alpha$ that protected individuals from the consequences of sleep loss did not predominate in the subject populations, consistent with the possibility that these alleles are accompanied with susceptibility to other physiological challenges. Brain structure can also influence sensitivity to sleep loss; variation in functional connectivity between brain regions and hippocampal structure can predict the cognitive impact of sleep loss in human subjects (Yeo et al., 2015; Saletin et al., 2016). While the neural and molecular mechanisms that connect these variations with susceptibility to sleep are not yet known, studies of model systems provide some insights into pathways that might provide protection from insufficient sleep. Drosophila and mouse 
studies have identified genetic pathways, including circadian rhythm (Mang et al., 2016; Ehlen et al., 2017), and metabolic factors (Thimgan et al., 2010, 2015), that can be manipulated to prevent rebound sleep following extended waking. It is important to note that each of these interventions can temporarily delay the accumulation of sleep debt, but it is unclear how long their protection persists and whether other consequences build as a result. Nonetheless, further examination of the external contexts and internal factors that can confer resilience to sleep loss may provide new insight into the neural functions of sleep and identify controllable interventions to facilitate rapid recovery from sleep loss.

\section{CONCLUSION}

In many contexts, sleep is vital for individuals to learn and adapt their behavior to best fit their environmental conditions. Sleep facilitates brain development and circuit refinement, and early life disruptions in sleep can result in long-lasting behavioral changes. Throughout the lifespan, sleep also impacts whether new memories can be effectively acquired and consolidated. While understanding the mechanisms that contribute to sleep-dependent plasticity remain an area of intense interest, many studies have already identified molecular and synaptic connectivity changes that occur during sleep to facilitate memory formation. More clearly identifying these

\section{REFERENCES}

Andretic, R., Swinderen, B. V., and Greenspan, R. J. (2005). Dopaminergic modulation of arousal in drosophila. Curr. Biol. 15, 1165-1175. doi: 10.1016/j.cub.2005.05.025

Aso, Y., Hattori, D., Yu, Y., Johnston, R. M., Iyer, N. A., Ngo, T.-T., et al. (2014a). The neuronal architecture of the mushroom body provides a logic for associative learning. Elife 3:e04577. doi: 10.7554/elife.04577

Aso, Y., Sitaraman, D., Ichinose, T., Kaun, K. R., Vogt, K., Belliart-Guérin, G., et al. (2014b). Mushroom body output neurons encode valence and guide memorybased action selection in Drosophila. Elife 3:e04580. doi: 10.7554/elife.04580

Aton, S. J., Broussard, C., Dumoulin, M., Seibt, J., Watson, A., Coleman, T., et al. (2013). Visual experience and subsequent sleep induce sequential plastic changes in putative inhibitory and excitatory cortical neurons. Proc. Natl. Acad. Sci. U.S.A. 110, 3101-3106. doi: 10.1073/pnas. 1208093110

Aton, S. J., Seibt, J., Dumoulin, M., Jha, S. K., Steinmetz, N., Coleman, T., et al. (2009). Mechanisms of sleep-dependent consolidation of cortical plasticity. Neuron 61, 454-466. doi: 10.1016/j.neuron.2009.01.007

Aton, S. J., Suresh, A., Broussard, C., and Frank, M. G. (2014). Sleep promotes cortical response potentiation following visual experience. Sleep 37, 1163-1170. doi: 10.5665/sleep.3830

Backhaus, J., Born, J., Hoeckesfeld, R., Fokuhl, S., Hohagen, F., and Junghanns, K. (2007). Midlife decline in declarative memory consolidation is correlated with a decline in slow wave sleep. Learn Mem. 14, 336-341. doi: 10.1101/lm.4 70507

Banks, S., and Dinges, D. F. (2007). Behavioral and physiological consequences of sleep restriction. J. Clin. Sleep Med. 03, 519-528. doi: 10.5664/jcsm.26918

Beckwith, E. J., Geissmann, Q., French, A. S., and Gilestro, G. F. (2017). Regulation of sleep homeostasis by sexual arousal. Elife 6:e27445. doi: 10.7554/elife.27445

Bjorness, T. E., Kulkarni, A., Rybalchenko, V., Suzuki, A., Bridges, C., Harrington, A. J., et al. (2020). An essential role for MEF2C in the cortical response to loss of sleep in mice. Elife 9:e58331. doi: 10.7554/elife.58331 mechanisms and developing strategies to manipulate them could open opportunities to support cognitive processing during sleep loss. Finally, individuals exhibit varying responses to sleep loss due to intrinsic and environmental factors. Understanding the benefits and detriments of variations in sleep, as well as the biological basis for inter-individual differences, will help resolve the function(s) of sleep and elucidate how sleep patterns affect future behavior.

\section{AUTHOR CONTRIBUTIONS}

JW and JD wrote sections of the manuscript. All authors contributed to manuscript revision, read, and approved the submitted version.

\section{FUNDING}

This work had support from NIH/NINDS R01NS105967 to JD and a Jessamine K. Hilliard UCLA Neurobiology Graduate Student Grant to JW.

\section{ACKNOWLEDGMENTS}

We thank members of the Donlea lab for helpful suggestions and comments.
Blumberg, M. S., Coleman, C. M., Gerth, A. I., and McMurray, B. (2013). Spatiotemporal structure of REM sleep twitching reveals developmental origins of motor synergies. Curr. Biol. 23, 2100-2109. doi: 10.1016/j.cub.2013.08.055

Blumberg, M. S., Coleman, C. M., Sokoloff, G., Weiner, J. A., Fritzsch, B., and McMurray, B. (2015). Development of twitching in sleeping infant mice depends on sensory experience. Curr. Biol. 25, 656-662. doi: 10.1016/j.cub.2015.01.022

Blumberg, M. S., Dooley, J. C., and Sokoloff, G. (2020). The developing brain revealed during sleep. Curr. Opin. Physiol. 15, 14-22. doi: 10.1016/j.cophys.2019.11.002

Bridi, M. C. D., Aton, S. J., Seibt, J., Renouard, L., Coleman, T., and Frank, M. G. (2015). Rapid eye movement sleep promotes cortical plasticity in the developing brain. Sci. Adv. 1:e1500105. doi: 10.1126/sciadv.1500105

Bushey, D., Tononi, G., and Cirelli, C. (2011). Sleep and synaptic homeostasis: structural evidence in Drosophila. Science 332, 1576-1581. doi: $10.1126 /$ science.1202839

Cairney, S. A., Guttesen, A. Á. V., Marj, N. E., and Staresina, B. P. (2018). Memory consolidation is linked to spindle-mediated information processing during sleep. Curr. Biol. 28, 948-954.e4. doi: 10.1016/j.cub.2018.01.087

Carrier, J., Viens, I., Poirier, G., Robillard, R., Lafortune, M., Vandewalle, G., et al. (2011). Sleep slow wave changes during the middle years of life. Eur. J. Neurosci. 33, 758-766. doi: 10.1111/j.1460-9568.2010.07543.x

Cauter, E. V., Leproult, R., and Plat, L. (2000). Age-related changes in slow wave sleep and REM sleep and relationship with growth hormone and cortisol levels in healthy men. JAMA 284, 861-868. doi: 10.1001/jama.284.7.861

Chouhan, N. S., Griffith, L. C., Haynes, P., and Sehgal, A. (2021). Availability of food determines the need for sleep in memory consolidation. Nature 589, 582-585. doi: 10.1038/s41586-020-2997-y

Clawson, B. C., Durkin, J., Suresh, A. K., Pickup, E. J., Broussard, C. G., and Aton, S. J. (2018). Sleep promotes, and sleep loss inhibits, selective changes in firing rate, response properties and functional connectivity of primary visual cortex neurons. Front. Syst Neurosci. 12, 40. doi: 10.3389/fnsys.2018.00040 
Clawson, B. C., Pickup, E. J., Ensing, A., Geneseo, L., Shaver, J., Gonzalez-Amoretti, J., et al. (2021). Causal role for sleep-dependent reactivation of learningactivated sensory ensembles for fear memory consolidation. Nat. Commun. 12, 1200. doi: 10.1038/s41467-021-21471-2

Clem, R. L., and Barth, A. (2006). Pathway-specific trafficking of native AMPARs by in vivo experience. Neuron 49, 663-670. doi: 10.1016/j.neuron.2006.01.019

Cohen, S., Kaplan, Z., Zohar, J., and Cohen, H. (2017). Preventing sleep on the first resting phase following a traumatic event attenuates anxiety-related responses. Behav. Brain Res. 320, 450-456. doi: 10.1016/j.bbr.2016.10.039

Cooke, S. F., and Bliss, T. V. P. (2006). Plasticity in the human central nervous system. Brain 129, 1659-1673. doi: 10.1093/brain/awl082

Cossío, L. F., de, Guzmán, A., Veldt, S., van der, and Luheshi, G. N. (2017). Prenatal infection leads to ASD-like behavior and altered synaptic pruning in the mouse offspring. Brain Behav. Immun. 63, 88-98. doi: 10.1016/j.bbi.2016.09.028

Delorme, J., Wang, L., Kuhn, F. R., Kodoth, V., Ma, J., Martinez, J. D., et al. (2021). Sleep loss drives acetylcholine- and somatostatin interneuron-mediated gating of hippocampal activity to inhibit memory consolidation. Proc. Natl. Acad. Sci. U.S.A. 118:e2019318118. doi: 10.1073/pnas.2019318118

Dennis, L. E., Wohl, R. J., Selame, L. A., and Goel, N. (2017). Healthy adults display long-term trait-like neurobehavioral resilience and vulnerability to sleep loss. Sci. Rep. 7, 14889. doi: 10.1038/s41598-017-14006-7

Diekelmann, S., and Born, J. (2010). The memory function of sleep. Nat. Rev. Neurosci. 11, 114-126. doi: 10.1038/nrn2762

Diering, G. H., Nirujogi, R. S., Roth, R. H., Worley, P. F., Pandey, A., and Huganir, R. L. (2017). Homerla drives homeostatic scaling-down of excitatory synapses during sleep. Science 355, 511-515. doi: 10.1126/science.aai8355

Dijk, D.-J., Groeger, J. A., Stanley, N., and Deacon, S. (2010). Age-related reduction in daytime sleep propensity and nocturnal slow wave sleep. Sleep 33, 211-223. doi: $10.1093 /$ sleep/33.2.211

Dinges, D. F., Pack, F., Williams, K., Gillen, K. A., Powell, J. W., Ott, G. E., et al. (1997). Cumulative sleepiness, mood disturbance, and psychomotor vigilance performance decrements during a week of sleep restricted to 4-5 hours per night. Sleep 20, 267-277.

Dissel, S., Angadi, V., Kirszenblat, L., Suzuki, Y., Donlea, J., Klose, M., et al. (2015). Sleep restores behavioral plasticity to Drosophila mutants. Curr. Biol. 25, 1270-1281. doi: 10.1016/j.cub.2015.03.027

Donlea, J. M., Leahy, A., Thimgan, M. S., Suzuki, Y., Hughson, B. N., Sokolowski, M. B., et al. (2012). Foraging alters resilience/vulnerability to sleep disruption and starvation in Drosophila. Proc. Natl. Acad. Sci. U.S.A. 109, 2613-2618. doi: $10.1073 /$ pnas.1112623109

Durmer, J. S., and Dinges, D. F. (2005). Neurocognitive consequences of sleep deprivation. Semin. Neurol. 25, 117-129. doi: 10.1055/s-2005-867080

Ednick, M., Cohen, A. P., McPhail, G. L., Beebe, D., Simakajornboon, N., and Amin, R. S. (2009). A review of the effects of sleep during the first year of life on cognitive, psychomotor, and temperament development. Sleep 32, 1449-1458. doi: 10.1093/sleep/32.11.1449

Ehlen, J. C., Brager, A. J., Baggs, J., Pinckney, L., Gray, C. L., DeBruyne, J. P., et al. (2017). Bmal1 function in skeletal muscle regulates sleep. Elife 6:e26557. doi: 10.7554/elife. 26557

Feinberg, and Carlson, V. R. (1968). Sleep variables as a function of age in man. Arch. Gen. Psychiatry 18, 239-250. doi: 10.1001/archpsyc.1968.01740020111014

Feinberg, I., and Campbell, I. G. (2010). Sleep EEG changes during adolescence: an index of a fundamental brain reorganization. Brain Cogn. 72, 56-65. doi: 10.1016/j.bandc.2009.09.008

Foote, S. L., Aston-Jones, G., and Bloom, F. E. (1980). Impulse activity of locus coeruleus neurons in awake rats and monkeys is a function of sensory stimulation and arousal. Proc. Natl. Acad. Sci. U.S.A. 77, 3033-3037. doi: 10.1073/pnas.77.5.3033

Frank, M. G., Issa, N. P., and Stryker, M. P. (2001). Sleep enhances plasticity in the developing visual cortex. Neuron 30, 275-287. doi: 10.1016/s0896-6273(01)00279-3

Gaine, M. E., Bahl, E., Chatterjee, S., Michaelson, J. J., Abel, T., and Lyons, L. C. (2021). Altered hippocampal transcriptome dynamics following sleep deprivation. Mol. Brain 14, 125. doi: 10.1186/s13041-021-00835-1

Gais, S., Albouy, G., Boly, M., Dang-Vu, T. T., Darsaud, A., Desseilles, M., et al. (2007). Sleep transforms the cerebral trace of declarative memories. Proc. Natl. Acad. Sci. U.S.A. 104, 18778-18783. doi: 10.1073/pnas.0705454104
Ganguly-Fitzgerald, I., Donlea, J. M., and Shaw, P. J. (2006). Waking experience affects sleep need in Drosophila. Science 313, 1775-1781. doi: $10.1126 /$ science. 1130408

Gilestro, G. F., Tononi, G., and Cirelli, C. (2009). Widespread changes in synaptic markers as a function of sleep and wakefulness in Drosophila. Science 324, 109-112. doi: 10.1126/science.1166673

Glanz, R. M., Dooley, J. C., Sokoloff, G., and Blumberg, M. S. (2021). Sensory coding of limb kinematics in motor cortex across a key developmental transition. J. Neurosci. 41, 6905-6918. doi: 10.1523/jneurosci.0921-21.2021

Gogolla, N., Takesian, A. E., Feng, G., Fagiolini, M., and Hensch, T. K. (2014). Sensory integration in mouse insular cortex reflects GABA circuit maturation. Neuron 83, 894-905. doi: 10.1016/j.neuron.2014.06.033

Grandner, M. A., Hale, L., Moore, M., and Patel, N. P. (2010). Mortality associated with short sleep duration: the evidence, the possible mechanisms, and the future. Sleep Med. Rev. 14, 191-203. doi: 10.1016/j.smrv.2009. 07.006

Graves, L. A., Heller, E. A., Pack, A. I., and Abel, T. (2003). Sleep deprivation selectively impairs memory consolidation for contextual fear conditioning. Learn Mem. 10, 168-176. doi: 10.1101/lm.48803

Gruart, A., Muñoz, M. D., and Delgado-García, J. M. (2006). Involvement of the CA3-CA1 synapse in the acquisition of associative learning in behaving mice. J. Neurosci. 26, 1077-1087. doi: 10.1523/jneurosci.2834-05.2006

Halbower, A. C., Degaonkar, M., Barker, P. B., Earley, C. J., Marcus, C. L., Smith, P. L., et al. (2006). Childhood obstructive sleep apnea associates with neuropsychological deficits and neuronal brain injury. PLoS Med. 3:e301. doi: 10.1371/journal.pmed.0030301

Hanlon, E. C., Faraguna, U., Vyazovskiy, V. V., Tononi, G., and Cirelli, C. (2009). Effects of skilled training on sleep slow wave activity and cortical gene expression in the rat. Sleep 32, 719-729. doi: 10.1093/sleep/32.6.719

Havekes, R., Park, A. J., Tudor, J. C., Luczak, V. G., Hansen, R. T., Ferri, S. L., et al. (2016). Sleep deprivation causes memory deficits by negatively impacting neuronal connectivity in hippocampal area CA1. Elife 5:e13424. doi: 10.7554/eLife.13424

Haynes, P. R., Christmann, B. L., and Griffith, L. C. (2015). A single pair of neurons links sleep to memory consolidation in Drosophila melanogaster. Elife 4, R774. doi: 10.7554/elife.03868

Heckman, P. R. A., Kuhn, F. R., Meerlo, P., and Havekes, R. (2020). A brief period of sleep deprivation negatively impacts the acquisition, consolidation, and retrieval of object-location memories. Neurobiol. Learn. Mem. 175, 107326. doi: 10.1016/j.nlm.2020.107326

Hendricks, J. C., Finn, S. M., Panckeri, K. A., Chavkin, J., Williams, J. A., Sehgal, A., et al. (2000). Rest in Drosophila is a sleep-like state. Neuron 25, 129-138. doi: 10.1016/s0896-6273(00)80877-6

Hengen, K. B., Pacheco, A. T., McGregor, J. N., Hooser, S. D. V., and Turrigiano, G. G. (2016). Neuronal firing rate homeostasis is inhibited by sleep and promoted by wake. Cell 165, 180-191. doi: 10.1016/j.cell.2016.01.046

Hige, T., Aso, Y., Modi, M. N., Rubin, G. M., and Turner, G. C. (2015). Heterosynaptic plasticity underlies aversive olfactory learning in Drosophila. Neuron 88, 985-998. doi: 10.1016/j.neuron.2015.11.003

Huang, S., Piao, C., Beuschel, C. B., Götz, T., and Sigrist, S. J. (2020). Presynaptic active zone plasticity encodes sleep need in Drosophila. Curr. Biol. 30, 1077-1091. doi: 10.1016/j.cub.2020.01.019

Hubel, D. H., and Wiesel, T. N. (1970). The period of susceptibility to the physiological effects of unilateral eye closure in kittens. J. Physiol. 206, 419-436. doi: 10.1113/jphysiol.1970.sp009022

Huber, R., Mäki, H., Rosanova, M., Casarotto, S., Canali, P., Casali, A. G., et al. (2013). Human cortical excitability increases with time awake. Cereb. Cortex 23, 1-7. doi: 10.1093/cercor/bhs014

Huber, R., Tononi, G., and Cirelli, C. (2007). Exploratory behavior, cortical BDNF expression, and sleep homeostasis. Sleep 30, 129-139. doi: $10.1093 /$ sleep/30.2.129

Hughes, J. R. (1958). Post-tetanic potentiation. Physiol. Rev. 38, 91-113. doi: 10.1152/physrev.1958.38.1.91

Izumi, Y., Clifford, D. B., and Zorumski, C. F. (1992). Norepinephrine reverses N-methyl-d-aspartate-mediated inhibition of long-term potentiation in rat hippocampal slices. Neurosci. Lett. 142, 163-166. doi: 10.1016/0304-3940(92)90364-d 
Izumi, Y., and Zorumski, C. F. (1999). Norepinephrine promotes long-term potentiation in the adult rat hippocampus in vitro. Synapse 31, 196-202. doi: 10.1002/(sici)1098-2396(19990301)31:3<196::aid-syn4>3.0.co;2-k

Jha, S. K., Jones, B. E., Coleman, T., Steinmetz, N., Law, C.-T., Griffin, G., et al. (2005). Sleep-dependent plasticity requires cortical activity. J. Neurosci. Off. J. Soc. Neurosci. 25, 9266-9274. doi: 10.1523/jneurosci.2722-05.2005

Jones, C. E., Opel, R. A., Kaiser, M. E., Chau, A. Q., Quintana, J. R., Nipper, M. A., et al. (2019). Early-life sleep disruption increases parvalbumin in primary somatosensory cortex and impairs social bonding in prairie voles. Sci. Adv. 5:eaav5188. doi: 10.1126/sciadv.aav5188

Jouvet-Mounier, D., Astic, L., and Lacote, D. (1970). Ontogenesis of the states of sleep in rat, cat, and guinea pig during the first postnatal month. Dev. Psychobiol. 2, 216-239. doi: 10.1002/dev.420020407

Kales, A., Wilson, T., Kales, J. D., Jacobson, A., Paulson, M. J., Kollar, E., et al. (1967). Measurements of all-night sleep in normal elderly persons: effects of aging*. J. Am. Geriatr. Soc. 15, 405-414. doi: 10.1111/j.1532-5415.1967.tb02072.x

Kayser, M. S., Yue, Z., and Sehgal, A. (2014). A critical period of sleep for development of courtship circuitry and behavior in Drosophila. Science 344, 269-274. doi: 10.1126/science. 1250553

Keene, A. C., Duboué, E. R., McDonald, D. M., Dus, M., Suh, G. S. B., Waddell, S., et al. (2010). Clock and cycle limit starvation-induced sleep loss in Drosophila. Curr. Biol. 20, 1209-1215. doi: 10.1016/j.cub.2010.05.029

Khazipov, R., Sirota, A., Leinekugel, X., Holmes, G. L., Ben-Ari, Y., and Buzsáki, G. (2004). Early motor activity drives spindle bursts in the developing somatosensory cortex. Nature 432, 758-761. doi: 10.1038/natu re03132

Khlghatyan, J., Evstratova, A., Bozoyan, L., Chamberland, S., Chatterjee, D., Marakhovskaia, A., et al. (2020). Fxrl regulates sleep and synaptic homeostasis. EMBO J. 39:e103864. doi: 10.15252/embj.2019 103864

Kim, H.-J., Cho, M.-H., Shim, W. H., Kim, J. K., Jeon, E.-Y., Kim, D.H., et al. (2017). Deficient autophagy in microglia impairs synaptic pruning and causes social behavioral defects. Mol. Psychiatry 22, 1576-1584. doi: $10.1038 / \mathrm{mp} .2016 .103$

Kirszenblat, L., Yaun, R., and Swinderen, B., van (2019). Visual experience drives sleep need in Drosophila. Sleep 8, 269. doi: 10.1093/sleep/zsz102

Kleim, B., Wysokowsky, J., Schmid, N., Seifritz, E., and Rasch, B. (2016). Effects of sleep after experimental trauma on intrusive emotional memories. Sleep 39, 2125-2132. doi: 10.5665/sleep.6310

Knutson, K. L., Spiegel, K., Penev, P., and Cauter, E. V. (2007). The metabolic consequences of sleep deprivation. Sleep Med. Rev. 11, 163-178. doi: 10.1016/j.smrv.2007.01.002

Konopaske, G. T., Lange, N., Coyle, J. T., and Benes, F. M. (2014). Prefrontal cortical dendritic spine pathology in schizophrenia and bipolar disorder. Jama Psychiatry 71, 1323-1331. doi: 10.1001/jamapsychiatry.2014.1582

Krishnan, H. C., Gandour, C. E., Ramos, J. L., Wrinkle, M. C., Sanchez-Pacheco, J. J., and Lyons, L. C. (2016). Acute sleep deprivation blocks short- and long-term operant memory in aplysia. Sleep 39, 2161-2171. doi: 10.5665/sleep.6320

Kröger, S., and Watkins, B. (2021). Muscle spindle function in healthy and diseased muscle. Skelet. Muscle 11, 3. doi: 10.1186/s13395-020-00258-x

Lamon, S., Morabito, A., Arentson-Lantz, E., Knowles, O., Vincent, G. E., Condo, D., et al. (2021). The effect of acute sleep deprivation on skeletal muscle protein synthesis and the hormonal environment. Physiol. Rep. 9:e14660. doi: 10.14814/phy2.14660

Lei, Z., Chen, K., Li, H., Liu, H., and Guo, A. (2013). The GABA system regulates the sparse coding of odors in the mushroom bodies of Drosophila. Biochem. Biophys. Res. Commun. 436, 35-40. doi: 10.1016/j.bbrc.2013.05.036

Lesku, J. A., Rattenborg, N. C., Valcu, M., Vyssotski, A. L., Kuhn, S., Kuemmeth, F., et al. (2012). Adaptive sleep loss in polygynous pectoral sandpipers. Science 337, 1654-1658. doi: 10.1126/science. 1220939

Li, F., Lindsey, J. W., Marin, E. C., Otto, N., Dreher, M., Dempsey, G., et al. (2020). The connectome of the adult Drosophila mushroom body provides insights into function. Elife 9:e62576. doi: 10.7554/elife.62576

Li, W., Ma, L., Yang, G., and Gan, W.-B. (2017). REM sleep selectively prunes and maintains new synapses in development and learning. Nat. Neurosci. 20, 427-437. doi: 10.1038/nn.4479
Li, X., Yu, F., and Guo, A. (2009). Sleep deprivation specifically impairs short-term olfactory memory in Drosophila. Sleep 32, 1417-1424.

Lin, A. C., Bygrave, A. M., Calignon, A., de, Lee, T., and Miesenböck, G. (2014). Sparse, decorrelated odor coding in the mushroom body enhances learned odor discrimination. Nat. Neurosci. 17, 559-568. doi: 10.1038/nn.3660

Liu, Z.-W., Faraguna, U., Cirelli, C., Tononi, G., and Gao, X.-B. (2010). Direct evidence for wake-related increases and sleep-related decreases in synaptic strength in rodent cortex. J. Neurosci. Off. J. Soc. Neurosci. 30, 8671-8675. doi: 10.1523/jneurosci.1409-10.2010

Lo, J. C., Chong, P. L. H., Ganesan, S., Leong, R. L. F., and Chee, M. W. L. (2016). Sleep deprivation increases formation of false memory. J. Sleep Res. 25, 673-682. doi: 10.1111/jsr.12436

Lubenov, E. V., and Siapas, A. G. (2008). Decoupling through synchrony in neuronal circuits with propagation delays. Neuron 58, 118-131. doi: 10.1016/j.neuron.2008.01.036

Lyamin, O., Pryaslova, J., Kosenko, P., and Siegel, J. (2007). Behavioral aspects of sleep in bottlenose dolphin mothers and their calves. Physiol. Behav. 92, 725-733. doi: 10.1016/j.physbeh.2007.05.064

Lyamin, O., Pryaslova, J., Lance, V., and Siegel, J. (2005). Continuous activity in cetaceans after birth. Nature 435, 1177-1177. doi: 10.1038/4351177a

Lyamin, O. I., Kosenko, P. O., Korneva, S. M., Vyssotski, A. L., Mukhametov, L. M., and Siegel, J. M. (2018). Fur seals suppress REM sleep for very long periods without subsequent rebound. Curr. Biol. 28, 2000.e2-2005.e2. doi: 10.1016/j.cub.2018.05.022

Lyamin, O. I., Manger, P. R., Ridgway, S. H., Mukhametov, L. M., and Siegel, J. M. (2008). Cetacean sleep: an unusual form of mammalian sleep. Neurosci. Biobehav. Rev. 32, 1451-1484. doi: 10.1016/j.neubiorev.2008.05.023

Lyamin, O. I., Mukhametov, L. M., and Siegel, J. M. (2017). Sleep in the northern fur seal. Curr. Opin. Neurobiol. 44, 144-151. doi: 10.1016/j.conb.2017.04.009

Machado, D. R., Afonso, D. J., Kenny, A. R., Öztürk-Çolak, A. and Moscato, E. H., Mainwaring, B., et al. (2017). Identification of octopaminergic neurons that modulate sleep suppression by male sex drive. Elife 6, 1717. doi: $10.7554 /$ elife. 23130

Mander, B. A., Winer, J. R., and Walker, M. P. (2017). Sleep and human aging. Neuron 94, 19-36. doi: 10.1016/j.neuron.2017.02.004

Mang, G. M., Spada, F. L., Emmenegger, Y., Chappuis, S., Ripperger, J. A., Albrecht, U., et al. (2016). Altered sleep homeostasis in Rev-erb $\alpha$ knockout mice. Sleep 39, 589-601. doi: 10.5665/sleep.5534

Marks, G. A., Shaffery, J. P., Oksenberg, A., Speciale, S. G., and Roffwarg, H. P. (1995). A functional role for REM sleep in brain maturation. Behav. Brain Res. 69, 1-11. doi: 10.1016/0166-4328(95)00018-o

McDermott, C. M., LaHoste, G. J., Chen, C., Musto, A., Bazan, N. G., and Magee, J. C. (2003). Sleep deprivation causes behavioral, synaptic, and membrane excitability alterations in hippocampal neurons. J. Neurosci. 23, 9687-9695. doi: 10.1523/jneurosci.23-29-09687.2003

Milinski, L., Fisher, S. P., Cui, N., McKillop, L. E., Blanco-Duque, C., Ang, G., et al. (2021). Waking experience modulates sleep need in mice. BMC Biol. 19:65. doi: 10.1186/s12915-021-00982-w

Mohns, E. J., and Blumberg, M. S. (2010). Neocortical activation of the hippocampus during sleep in infant rats. J. Neurosci. 30, 3438-3449. doi: 10.1523/jneurosci.4832-09.2010

Montes-Rodríguez, C. J., Rueda-Orozco, P. E., and Prospéro-García, O. (2019). Total sleep deprivation impairs fear memory retrieval by decreasing the basolateral amygdala activity. Brain Res. 1719, 17-23. doi: 10.1016/j.brainres.2019.05.030

Naegeli, C., Zeffiro, T., Piccirelli, M., Jaillard, A., Weilenmann, A., Hassanpour, K., et al. (2018). Locus coeruleus activity mediates hyperresponsiveness in posttraumatic stress disorder. Biol. Psychiatry 83, 254-262. doi: 10.1016/j.biopsych.2017.08.021

Nath, R. D., Bedbrook, C. N., Abrams, M. J., Basinger, T., Bois, J. S., Prober, D. A., et al. (2017). The jellyfish Cassiopea exhibits a sleep-like state. Curr. Biol. 27, p2984.e3-2990.e3. doi: 10.1016/j.cub.2017.08.014

Neniskyte, U., and Gross, C. T. (2017). Errant gardeners: glial-cell-dependent synaptic pruning and neurodevelopmental disorders. Nat. Rev. Neurosci. 18, 658-670. doi: 10.1038/nrn.2017.110

Niethard, N., Brodt, S., and Born, J. (2021). Cell-type-specific dynamics of calcium activity in cortical circuits over the course of slow-wave 
sleep and rapid eye movement sleep. J. Neurosci. 41, 4212-4222. doi: 10.1523/jneurosci.1957-20.2021

Norimoto, H., Makino, K., Gao, M., Shikano, Y., Okamoto, K., Ishikawa, T., et al. (2018). Hippocampal ripples down-regulate synapses. Science 359, 1524-1527. doi: 10.1126/science.aao0702

O’Brien, L. M., Mervis, C. B., Holbrook, C. R., Bruner, J. L., Klaus, C. J., Rutherford, J., et al. (2004). Neurobehavioral implications of habitual snoring in children. Pediatrics 114, 44-49. doi: 10.1542/peds.114.1.44

Ong, J. L., Lau, T. Y., Lee, X. K., Rijn, E., van, and Chee, M. W. L. (2020). A daytime nap restores hippocampal function and improves declarative learning. Sleep 43:zsaa058. doi: 10.1093/sleep/zsaa058

Owald, D., Felsenberg, J., Talbot, C. B., Das, G., Perisse, E., Huetteroth, W., et al. (2015). Activity of defined mushroom body output neurons underlies learned olfactory behavior in Drosophila. Neuron 86, 417-427. doi: 10.1016/j.neuron.2015.03.025

Pace-Schott, E. F., Germain, A., and Milad, M. R. (2015). Effects of sleep on memory for conditioned fear and fear extinction. Psychol. Bull. 141, 835-857. doi: 10.1037/bul0000014

Pacheco, A. T., Bottorff, J., Gao, Y., and Turrigiano, G. G. (2021). Sleep promotes downward firing rate homeostasis. Neuron 109, 530.e6-544.e6. doi: 10.1016/j.neuron.2020.11.001

Palmer, C. A., and Alfano, C. A. (2017). Sleep and emotion regulation: an organizing, integrative review. Sleep Med. Rev. 31, 6-16. doi: 10.1016/j.smrv.2015.12.006

Paolicelli, R. C., Bolasco, G., Pagani, F., Maggi, L., Scianni, M., Panzanelli, P., et al. (2011). Synaptic pruning by microglia is necessary for normal brain development. Science 333, 1456-1458. doi: 10.1126/scienc e.1202529

Passerin, A. M., Cano, G., Rabin, B. S., Delano, B. A., Napier, J. L., and Sved, A. F. (2000). Role of locus coeruleus in foot shock-evoked fos expression in rat brain. Neuroscience 101, 1071-1082. doi: 10.1016/s0306-4522(00) 00372-9

Poe, G. R. (2017). Sleep is for forgetting. J. Neurosci. 37, 464-473. doi: 10.1523/jneurosci.0820-16.2017

Porcheret, K., Holmes, E. A., Goodwin, G. M., Foster, R. G., and Wulff, K. (2015). Psychological effect of an analogue traumatic event reduced by sleep deprivation. Sleep 38, 1017-1025. doi: 10.5665/sleep.4802

Puentes-Mestril, C., Delorme, J., Wang, L., Donnelly, M., Popke, D., Jiang, S., et al. (2021). Sleep loss drives brain region-specific and cell type-specific alterations in ribosome-associated transcripts involved in synaptic plasticity and cellular timekeeping. J. Neurosci. 41, 5386-5398. doi: 10.1523/jneurosci.1883-20.2021

Puentes-Mestril, C., Roach, J., Niethard, N., Zochowski, M., and Aton, S. J. (2019). How rhythms of the sleeping brain tune memory and synaptic plasticity. Sleep 42:zsz095. doi: 10.1093/sleep/zsz095

Raccuglia, D., Huang, S., Ender, A., Heim, M.-M., Laber, D., Suárez-Grimalt, R., et al. (2019). Network-specific synchronization of electrical slow-wave oscillations regulates sleep drive in Drosophila. Curr. Biol. 29, 3611-3621. doi: 10.1016/j.cub.2019.08.070

Raizen, D. M., Zimmerman, J. E., Maycock, M. H., Ta, U. D., You, Y., Sundaram, M. V., et al. (2008). Lethargus is a Caenorhabditis elegans sleep-like state. Nature 451, 569-572. doi: 10.1038/nature06535

Rasch, B., and Born, J. (2013). About sleep's role in memory. Physiol. Rev. 93, 681-766. doi: 10.1152/physrev.00032.2012

Rattenborg, N. C., Voirin, B., Cruz, S. M., Tisdale, R., Dell'Omo, G., Lipp, H.-P., et al. (2016). Evidence that birds sleep in mid-flight. Nat. Commun. 7:12468. doi: $10.1038 /$ ncomms 12468

Raven, F., Meerlo, P., Zee, E. A. V., der, Abel, T., and Havekes, R. (2019). A brief period of sleep deprivation causes spine loss in the dentate gyrus of mice. Neurobiol. Learn. Mem. 160, 83-90. doi: 10.1016/j.nlm.2018.03.018

Rechtschaffen, A., and Bergmann, B. M. (1995). Sleep deprivation in the rat by the disk-over-water method. Behav. Brain Res. 69, 55-63. doi: 10.1016/0166-4328(95)00020-t

Rio-Bermudez, C. D., and Blumberg, M. S. (2018). Active sleep promotes functional connectivity in developing sensorimotor networks. Bioessays 40:e1700234. doi: 10.1002/bies.201700234

Roffwarg, H. P., Muzio, J. N., and Dement, W. C. (1966). Ontogenetic development of the human sleep-dream cycle. Science 152, 604-619. doi: $10.1126 /$ science.152.3722.604
Saletin, J. M., Goldstein-Piekarski, A. N., Greer, S. M., Stark, S., Stark, C. E., and Walker, M. P. (2016). Human hippocampal structure: a novel biomarker predicting mnemonic vulnerability to, and recovery from, sleep deprivation. $J$. Neurosci. 36, 2355-2363. doi: 10.1523/jneurosci.3466-15.2016

Satterfield, B. C., Wisor, J. P., Field, S. A., Schmidt, M. A., and Dongen, H. P. A. V. (2015). TNF $\alpha$ G308A polymorphism is associated with resilience to sleep deprivation-induced psychomotor vigilance performance impairment in healthy young adults. Brain Behav. Immun. 47, 66-74. doi: 10.1016/j.bbi.2014.12.009

Schabus, M., Hödlmoser, K., Gruber, G., Sauter, C., Anderer, P., Klösch, G., et al. (2006). Sleep spindle-related activity in the human EEG and its relation to general cognitive and learning abilities. Eur. J. Neurosci. 23, 1738-1746. doi: 10.1111/j.1460-9568.2006.04694.x

Scheffer, L. K., Xu, C. S., Januszewski, M., Lu, Z., Takemura, S., Hayworth, K. J., et al. (2020). A connectome and analysis of the adult Drosophila central brain. Elife 9:e57443. doi: 10.7554/elife.57443

Seugnet, L., Suzuki, Y., Donlea, J. M., Gottschalk, L., and Shaw, P. J. (2011). Sleep deprivation during early-adult development results in long-lasting learning deficits in adult Drosophila. Sleep 34, 137-146. doi: 10.1093/sleep/34.2.137

Seugnet, L., Suzuki, Y., Vine, L., Gottschalk, L., and Shaw, P. J. (2008). $\mathrm{D} 1$ receptor activation in the mushroom bodies rescues sleep-lossinduced learning impairments in Drosophila. Curr. Biol. 18, 1110-1117. doi: 10.1016/j.cub.2008.07.028

Shaw, P. J., Cirelli, C., Greenspan, R. J., and Tononi, G. (2000). Correlates of sleep and waking in Drosophila melanogaster. Science 287, 1834-1837. doi: $10.1126 /$ science.287.5459.1834

Siegel, J. M. (2008). Do all animals sleep? Trends Neurosci. 31, 208-213. doi: 10.1016/j.tins.2008.02.001

Singh, K., Ju, J. Y., Walsh, M. B., DiIorio, M. A., and Hart, A. C. (2014). Deep conservation of genes required for both Drosophila melanogaster and Caenorhabditis elegans sleep includes a role for dopaminergic signaling. Sleep 37, 1439-1451. doi: 10.5665/sleep.3990

Singh, P., and Donlea, J. M. (2020). Bidirectional regulation of sleep and synapse pruning after neural injury. Curr. Biol. 30, 1063.e3-1076.e3. doi: 10.1016/j.cub.2019.12.065

Sokoloff, G., Dooley, J. C., Glanz, R. M., Wen, R. Y., Hickerson, M. M., Evans, L. G., et al. (2021). Twitches emerge postnatally during quiet sleep in human infants and are synchronized with sleep spindles. Curr. Biol. 31, 3426.e4-3432.e4. doi: 10.1016/j.cub.2021.05.038

Sokoloff, G., Hickerson, M. M., Wen, R. Y., Tobias, M. E., McMurray, B., and Blumberg, M. S. (2020). Spatiotemporal organization of myoclonic twitching in sleeping human infants. Dev. Psychobiol. 62, 697-710. doi: 10.1002/dev.21954

Sokoloff, G., Uitermarkt, B. D., and Blumberg, M. S. (2015). REM sleep twitches rouse nascent cerebellar circuits: implications for sensorimotor development. Dev. Neurobiol. 75, 1140-1153. doi: 10.1002/dneu.22177

Spano, G. M., Banningh, S. W., Marshall, W., Vivo, L., de, Bellesi, M., Loschky, S. S., et al. (2019). Sleep deprivation by exposure to novel objects increases synapse density and axon-spine interface in the hippocampal CA1 region of adolescent mice. J. Neurosci. 39, 6613-6625. doi: 10.1523/JNEUROSCI.0380-19.2019

Spiegel, K., Knutson, K., Leproult, R., Tasali, E., and Cauter, E. V. (2005). Sleep loss: a novel risk factor for insulin resistance and type 2 diabetes. J. Appl. Physiol. 99, 2008-2019. doi: 10.1152/japplphysiol.00660.2005

Stanhope, B. A., Jaggard, J. B., Gratton, M., Brown, E. B., and Keene, A. C. (2020). Sleep regulates glial plasticity and expression of the engulfment receptor draper following neural injury. Curr. Biol. 30, 1092-1101.e3. doi: 10.1016/j.cub.2020.02.057

Stefanelli, T., Bertollini, C., Lüscher, C., Muller, D., and Mendez, P. (2016). Hippocampal somatostatin interneurons control the size of neuronal memory ensembles. Neuron 89, 1074-1085. doi: 10.1016/j.neuron.2016.01.024

Stickgold, R., and Walker, M. P. (2007). Sleep-dependent memory consolidation and reconsolidation. Sleep Med. 8, 331-343. doi: 10.1016/j.sleep.2007. 03.011

Tainton-Heap, L. A. L., Kirszenblat, L. C., Notaras, E. T., Grabowska, M. J., Jeans, R., Feng, K., et al. (2021). A paradoxical kind of sleep in Drosophila melanogaster. Curr. Biol. 31, 578.e6-590.e6. doi: 10.1016/j.cub.2020.10.081

Tang, G., Gudsnuk, K., Kuo, S.-H., Cotrina, M. L., Rosoklija, G., Sosunov, A., et al. (2014). Loss of mTOR-dependent macroautophagy causes autistic-like synaptic pruning deficits. Neuron 83, 1131-1143. doi: 10.1016/j.neuron.2014.07.040 
Tempesta, D., Socci, V., Gennaro, L. D., and Ferrara, M. (2018). Sleep and emotional processing. Sleep Med. Rev. 40, 183-195. doi: 10.1016/j.smrv.2017.12.005

Thimgan, M. S., Seugnet, L., Turk, J., and Shaw, P. J. (2015). Identification of genes associated with resilience/vulnerability to sleep deprivation and starvation in Drosophila. Sleep 38, 801-814. doi: 10.5665/sleep.4680

Thimgan, M. S., Suzuki, Y., Seugnet, L., Gottschalk, L., and Shaw, P. J. (2010). The perilipin homologue, lipid storage droplet 2, regulates sleep homeostasis and prevents learning impairments following sleep loss. PLoS Biol. 8:e1000466. doi: 10.1371/journal.pbio.1000466

Thomas, M. J., Moody, T. D., Makhinson, M., and O’Dell, T. J. (1996). Activity-dependent $\beta$-adrenergic modulation of low frequency stimulation induced LTP in the hippocampal CA1 region. Neuron 17, 475-482. doi: 10.1016/s0896-6273(00)80179-8

Tiriac, A., and Blumberg, M. S. (2016). Gating of reafference in the external cuneate nucleus during self-generated movements in wake but not sleep. Elife 5:e18749. doi: $10.7554 /$ elife. 18749

Tiriac, A., Uitermarkt, B. D., Fanning, A. S., Sokoloff, G., and Blumberg, M. S. (2012). Rapid whisker movements in sleeping newborn rats. Curr. Biol. 22, 2075-2080. doi: 10.1016/j.cub.2012.09.009

Tononi, G., and Cirelli, C. (2014). Sleep and the price of plasticity: from synaptic and cellular homeostasis to memory consolidation and integration. Neuron 81 , 12-34. doi: 10.1016/j.neuron.2013.12.025

Tudor, J. C., Davis, E. J., Peixoto, L., Wimmer, M. E., Tilborg, E., van, Park, A. J., et al. (2016). Sleep deprivation impairs memory by attenuating mTORC1dependent protein synthesis. Sci. Signal 9:ra41. doi: 10.1126/scisignal.aad4949

Tye, K. M., Stuber, G. D., Ridder, B., de Bonci, A., and Janak, P. H. (2008). Rapid strengthening of thalamo-amygdala synapses mediates cue-reward learning. Nature 453, 1253-1257. doi: 10.1038/nature06963

Vanderheyden, W. M., George, S. A., Urpa, L., Kehoe, M., Liberzon, I., and Poe, G. R. (2015). Sleep alterations following exposure to stress predict fearassociated memory impairments in a rodent model of PTSD. Exp. Brain Res. 233, 2335-2346. doi: 10.1007/s00221-015-4302-0

Vanderheyden, W. M., Poe, G. R., and Liberzon, I. (2014). Trauma exposure and sleep: using a rodent model to understand sleep function in PTSD. Exp. Brain Res. 232, 1575-1584. doi: 10.1007/s00221-014-3890-4

Vecsey, C. G., Baillie, G. S., Jaganath, D., Havekes, R., Daniels, A., Wimmer, M., et al. (2009). Sleep deprivation impairs cAMP signalling in the hippocampus. Nature 461, 1122-1125. doi: 10.1038/nature08488

Vienne, J., Spann, R., Guo, F., and Rosbash, M. (2016). Age-related reduction of recovery sleep and arousal threshold in Drosophila. Sleep 39, 1613-1624. doi: $10.5665 /$ sleep. 6032

Viola, A. U., Archer, S. N., James, L. M., Groeger, J. A., Lo, J. C. Y., Skene, D. J., et al. (2007). PER3 polymorphism predicts sleep structure and waking performance. Curr. Biol. 17, 613-618. doi: 10.1016/j.cub.2007.01.073

Viola, A. U., Chellappa, S. L., Archer, S. N., Pugin, F., Götz, T., Dijk, D.-J., et al. (2012). Interindividual differences in circadian rhythmicity and sleep homeostasis in older people: effect of a PER3 polymorphism. Neurobiol Aging 33, 1010.e17-27. doi: 10.1016/j.neurobiolaging.2011.10.024

Vivo, L., de Bellesi, M., Marshall, W., Bushong, E. A., Ellisman, M. H., Tononi, G., et al. (2017). Ultrastructural evidence for synaptic scaling across the wake/sleep cycle. Science 355, 507-510. doi: 10.1126/science.aah5982

Vivo, L., de, Nagai, H., Wispelaere, N. D., Spano, G. M., Marshall, W., Bellesi, M., et al. (2019). Evidence for sleep-dependent synaptic renormalization in mouse pups. Sleep 42:zsz184. doi: 10.1093/sleep/zsz184

Vyazovskiy, V. V., Cirelli, C., Pfister-Genskow, M., Faraguna, U., and Tononi, G. (2008). Molecular and electrophysiological evidence for net synaptic potentiation in wake and depression in sleep. Nat. Neurosci. 11, 200-208. doi: $10.1038 / \mathrm{nn} 2035$

Vyazovskiy, V. V., Olcese, U., Lazimy, Y. M., Faraguna, U., Esser, S. K., Williams, J. C., et al. (2009). Cortical firing and sleep homeostasis. Neuron 63, 865-878. doi: 10.1016/j.neuron.2009.08.024

Walker, M. P., Brakefield, T., Morgan, A., Hobson, J. A., and Stickgold, R. (2002). Practice with sleep makes perfect: sleep-dependent motor skill learning. Neuron 35, 205-211. doi: 10.1016/s0896-6273(02)00746-8
Wassing, R., Lakbila-Kamal, O., Ramautar, J. R., Stoffers, D., Schalkwijk, F., and Someren, E. J. W. V. (2019). Restless REM sleep impedes overnight amygdala adaptation. Curr. Biol. 29, 2351.e4-8.e4. doi: 10.1016/j.cub.2019.06.034

Watson, B. O., Levenstein, D., Greene, J. P., Gelinas, J. N., and Buzsáki, G. (2016). Network homeostasis and state dynamics of neocortical sleep. Neuron 90, 839-852. doi: 10.1016/j.neuron.2016.03.036

Weiss, J. T., and Donlea, J. M. (2021). Sleep deprivation results in diverse patterns of synaptic scaling across the Drosophila mushroom bodies. Curr. Biol. 31, 3248.e3-61.e3. doi: 10.1016/j.cub.2021.05.018

Wu, J., Zhou, Q., Li, J., Chen, Y., Shao, S., and Xiao, Y. (2021). Decreased restingstate alpha-band activation and functional connectivity after sleep deprivation. Sci. Rep. 11, 484. doi: 10.1038/s41598-020-79816-8

Yamazaki, E. M., Antler, C. A., Lasek, C. R., and Goel, N. (2020). Residual, differential neurobehavioral deficits linger after multiple recovery nights following chronic sleep restriction or acute total sleep deprivation. Sleep. 44:zsaa224. doi: 10.1093/sleep/zsaa224

Yamazaki, E. M., and Goel, N. (2019). Robust stability of trait-like vulnerability or resilience to common types of sleep deprivation in a large sample of adults. Sleep 43:zsz292. doi: 10.1093/sleep/zsz292

Yang, G., Lai, C. S. W., Cichon, J., Ma, L., Li, W., and Gan, W.-B. (2014). Sleep promotes branch-specific formation of dendritic spines after learning. Science 344, 1173-1178. doi: 10.1126/science. 1249098

Yap, M. H. W., Grabowska, M. J., Rohrscheib, C., Jeans, R., Troup, M., Paulk, A. C., et al. (2017). Oscillatory brain activity in spontaneous and induced sleep stages in flies. Nat. Commun. 8:1815. doi: 10.1038/s41467-017-0 2024-y

Yeo, B. T. T., Tandi, J., and Chee, M. W. L. (2015). Functional connectivity during rested wakefulness predicts vulnerability to sleep deprivation. Neuroimage 111, 147-158. doi: 10.1016/j.neuroimage.2015.02.018

Yizhar, O., Fenno, L. E., Prigge, M., Schneider, F., Davidson, T. J., O’Shea, D. J., et al. (2011). Neocortical excitation/inhibition balance in information processing and social dysfunction. Nature 477, 171-178. doi: 10.1038/nature10360

Yoo, S.-S., Hu, P. T., Gujar, N., Jolesz, F. A., and Walker, M. P. (2007). A deficit in the ability to form new human memories without sleep. Nat. Neurosci. 10, 385-392. doi: 10.1038/nn1851

Yurgel, M. E., Kakad, P., Zandawala, M., Nässel, D. R., Godenschwege, T. A., and Keene, A. C. (2019). A single pair of leucokinin neurons are modulated by feeding state and regulate sleep-metabolism interactions. PLoS Biol. 17:e2006409. doi: 10.1371/journal.pbio.20 06409

Zhdanova, I. V., Wang, S. Y., Leclair, O. U., and Danilova, N. P. (2001). Melatonin promotes sleep-like state in zebrafish11 published on the world wide web on 6 April 2001. Brain Res. 903, 263-268. doi: 10.1016/s0006-8993(01)0 2444-1

Zucker, R. S., and Regehr, W. G. (2002). Short-term synaptic plasticity. Annu. Rev. Physiol. 64, 355-405. doi: 10.1146/annurev.physiol.64.092501.1 14547

Conflict of Interest: The authors declare that the research was conducted in the absence of any commercial or financial relationships that could be construed as a potential conflict of interest.

Publisher's Note: All claims expressed in this article are solely those of the authors and do not necessarily represent those of their affiliated organizations, or those of the publisher, the editors and the reviewers. Any product that may be evaluated in this article, or claim that may be made by its manufacturer, is not guaranteed or endorsed by the publisher.

Copyright (c) 2022 Weiss and Donlea. This is an open-access article distributed under the terms of the Creative Commons Attribution License (CC BY). The use, distribution or reproduction in other forums is permitted, provided the original author(s) and the copyright owner(s) are credited and that the original publication in this journal is cited, in accordance with accepted academic practice. No use, distribution or reproduction is permitted which does not comply with these terms. 